\title{
Effects of SASH1 on melanoma cell proliferation and apoptosis in vitro
}

\author{
SHEYU LIN ${ }^{1,2}$, JUNYU ZHANG ${ }^{1}$, JIAWEI XU ${ }^{1}$, HONGLIAN WANG ${ }^{1}$, QING SANG ${ }^{1}$, \\ QINGHE XING ${ }^{1}$ and $\mathrm{LIN} \mathrm{HE}^{1}$ \\ ${ }^{1}$ Children's Hospital, Institute of Biomedical Sciences, Fudan University, Shanghai 200032; \\ ${ }^{2}$ School of Life Sciences, Nantong University, Nantong 226019, P.R. China
}

Received April 28, 2012; Accepted August 28, 2012

DOI: $10.3892 / \mathrm{mmr} .2012 .1099$

\begin{abstract}
The SAM and SH3 domain containing 1 (SASH1) gene was originally identified as a potential tumor suppressor gene in breast cancer, mapped on chromosome 6q24.3. The expression of SASH1 plays a prognostic role in human colon cancer. Its expression is frequently downregulated in several human malignancies. However, the biological function of SASH1 in melanoma cells is yet to be determined. In this study, in order to investigate the tumor suppressive effects of the SASH1 gene, an A-375 stable melanoma cell line was established, overexpressing the SASH1 gene. The stable cell line was examined using proliferation assay, apoptosis assay, cell cycle analysis and real-time PCR. The results indicated that the tumor suppressive activity of SASH1 derived from G2/M arrest in A-375 cells, and that the phosphorylation of $\mathrm{Cdc} 2$ or the disruption of cyclin B-Cdc2 binding may be responsible for the $\mathrm{G} 2 / \mathrm{M}$ arrest.
\end{abstract}

\section{Introduction}

Cancer is the second leading cause of mortality in the United States and some European countries, such as Finland and Scotland (1-3). The knowledge of molecular genetic mechanisms underlying tumorigenesis has increased since the discovery of the TP53 tumor suppressor gene (4-9). Tumor suppressor genes normally help prevent unrestrained cellular growth and promote DNA repair and cell cycle checkpoint activation.

SAM and SH3 domain containing 1 (SASH1), a novel tumor suppressor gene mapped on chromosome $6 \mathrm{q} 24.3$, is possibly involved in the tumorigenesis of breast and other solid tumors. It is a member of the SH3 domain-containing expressed in lymphocytes (SLY1) gene family that encodes

Correspondence to: Dr Lin He or Dr Qinghe Xing, Institutes of Biomedical Sciences, Fudan University, 138 Yixueyuan Road, Shanghai 200032, P.R. China

E-mail: helinhelin@gmail.com

E-mail: xingqinghe@hotmail.com

Key words: SAM and SH3 domain-containing 1, tumor suppressor gene, G2/M arrest signal adaptor proteins composed of several protein-protein interaction domains. The other members of this family are expressed mainly in haematopoietic cells, whereas SASH1 has demonstrated an ubiquitous expression. It is downregulated in the majority (74\%) of breast tumors in comparison with corresponding normal breast epithelial tissues. Moreover, the expression levels of SASH1 are strongly and significantly reduced in colon cancer of UICC stage II, III and IV, as well as in liver metastases. Additionally, Martini et al demonstrated that SASH1 plays a crucial role in tumor formation by regulating the adhesiveness and migratory behavior of cancer cells (10). Furthermore, Chen et al indicated that in the A549 lung cancer cells of the pcDNA3.1-SASH1 transfected group, cell viability, proliferation and migration were significantly reduced compared to the control cells, while a cell cycle arrest was observed in G1 (11). However, the specific mechanism by which SASH1 influences these biological behaviors is yet to be determined. Moreover, to date, no studies have been reported on the biological role of SASH1 in melanoma cells.

In order to examine the function of the SASH1 gene in melanoma, we transfected the SASH1 gene into the A-375 melanoma cells. Subsequently, we examined the changes in the relevant biological characteristics of the A-375 cell line and preliminarily analyzed the significance of the SASH1 gene in melanoma. We also investigated the correlation between SASH1 expression and the associated molecular changes in the cell cycle to provide further insight into the potential use of SASH1 for the targeted therapy of melanoma. The tumor suppressive effects of SASH1 occured due to the accumulation of cells at the G2/M stage of the cell cycle.

\section{Materials and methods}

Construction of recombinant plasmids. The wild-type fulllength DNA coding the human SASH1 gene was synthesized by Clontech Laboratory Incorporation and cloned into the pEGFP-C3 vector (Clontech, Palo Alto, CA, USA) to construct pEGFP-C3-SASH1, N-terminally tagged with green fluorescence protein (GFP).

Cell culture and transfection. The cells were cultured and maintained in DMEM high-glucose medium (Gibco BRL, Grand Island, NY, USA), containing 10\% Front FBS 
(Front Biomedicals, Dunedin, New Zealand), penicillin (100 U/ $\mathrm{ml})$ and streptomycin $(100 \mathrm{U} / \mathrm{ml})$, and were incubated at $37^{\circ} \mathrm{C}$ in a humidified incubator under an atmosphere of $5 \% \mathrm{CO}_{2}$. The cells transfected with pEGFP-C3 were used as the negative control. The cells transfected with pEGFP-C3-SASH1 [named A-375 (SASH1)] or pEGFP-C3 [named A-375 (EGFP)] were examined under a fluorescence microscope (Olympus, Tokyo, Japan) and a corresponding single cell clone was selected with neomycin. After culture propagation for certain periods of time, SASH1 gene expression was measured by western blot analysis.

Western blot analysis. Cells were lysed with cell lysis buffer for western blot analysis and immunoprecipitation (IP) (Beyotime Institute of Biotechnology, Jiangsu, China), containing protease inhibitors (Pierce Biotechnology, Rockford, IL, USA). GAPDH levels were used to normalize loading. SASH1 antibody was purchased from Bethyl laboratories Inc. (Montgomery, MA, USA) and the primary GAPDH antibody was purchased from Proteintech Group (Chicago, IL, USA).

Cell proliferation assay. Proliferation assay was carried out to assess cell viability in the A-375 (SASH1), A-375 (EGFP) and A-375 cell lines. Cells were seeded on 24-well plates and each experiment was performed in triplicate. After $48 \mathrm{~h}$, the cells were washed with PBS and assessed using a 3-(4, 5-dimethylthiazol-2-yl)-2,5-diphenyl tetrazolium bromide (MTT) (AppliChem, Darmstadt, Germany) assay.

Cell apoptosis assay. To investigate apoptotic body, cells were seeded on a 24-well plate and each assay was repeated 3 times. After $72 \mathrm{~h}$, cells were washed with PBS and stained with 4,6-diamidino-2-phenylindole (DAPI) according to the Genmed nuclear staining kit (Genmed Scientifics Inc., Shanghai, China). Stained cells were photographed under a Leica fluorescence convert microscope (Leica Camera AG, Mannheim, Germany).

To examine the rate of apoptosis, cells from each group (dish, $6 \mathrm{~cm}$ in diameter) were gently resuspended in $195 \mu \mathrm{l}$ of Annexin V-FITC binding buffer. Subsequently, $5 \mu 1$ of Annexin V-FITC were added followed by gentle mixing. The cells were then incubated for $10 \mathrm{~min}$ at room temperature in the dark and subsequently centrifuged at $1,000 \mathrm{x}$ g for $5 \mathrm{~min}$. The supernatant was discarded, and $190 \mu 1$ of Annexin V-FITC binding buffer was added to gently resuspend the cells. Finally, $10 \mu 1$ of PI staining solution were added and gently mixed with the cells. The cells were then placed on ice and analyzed immediately by flow cytometry.

Cell cycle analysis. Cell cycle analysis was carried out by flow cytometry (FCM). Briefly, A-375 (SASH1), A-375 (EGFP) and A-375 cell lines were seeded in $10-\mathrm{cm}$ dishes and each experiment was performed in 4 repeats. The experiments were carried out with the Genmed cell cycle analysis kit (Genmed Scientifics Inc.). Briefly, after $72 \mathrm{~h}$, the cells were digested with trypsin after washing twice with PBS and fixed in ethanol for $16 \mathrm{~h}$ at $4^{\circ} \mathrm{C}$. The samples were concentrated by removing the ethanol and treated with Genmed staining solution for $45 \mathrm{~min}$ at $37^{\circ} \mathrm{C}$ in the dark. Cell cycle distribution was determined using a flow cytometer (Beckman Coulter, Miami, FL, USA) and 10,000 cells were analyzed with Expo32 ADC Analysis software.
RNA extraction. RNA was extracted using the Aqua-Spin RNA Isolation Mini kit (Watson Biotechnologies, Shanghai, China). The concentration and quality of the isolated DNA and RNA were measured with a NanoDrop ND-1000 spectrophotometer (NanoDrop Technologies, Montchanin, DE, USA).

Real-time PCR. First-strand cDNA was synthesized using PrimeScript RT reagent kit according to the manufacturer's instructions (Takara, Ostu, Shiga, Japan). The CCNB1 (cyclin B), CDK1 (Cdc2), TP53 (p53) and WEE1 genes were co-amplified with a fragment of the glyceraldehyde 3-phosphate dehydrogenase (GAPDH) gene, which served as the internal standard. Q-PCR was conducted by the SYBR Premix Ex Taq kit (Takara, Ostu, Shiga, Japan) on the ABI 7900HT Fast Real-Time PCR System (Life Technologies, Carlsbad, CA, USA). The primer pairs are shown in Table I and the cycling conditions of 40 cycles of PCR were as follows: $95^{\circ} \mathrm{C} / 5 \mathrm{sec}$, $55^{\circ} \mathrm{C} / 30 \mathrm{sec}$ and $72^{\circ} \mathrm{C} / 30 \mathrm{sec}$. Each sample was run in 4 repeats and all the PCR data were analyzed with the ABI 7900HT system software 2.3 version.

Statistical analysis. Real-time PCR results were compared using one-way ANOVA analysis among 3 groups. All p-values were two-sided, and $\mathrm{p}<0.05$ was considered to indicate a statistically significant difference. SPSS software version 15.0 (SPSS Inc., Chicago, IL, USA) was used for all statistical analyses.

\section{Results}

Generation of SASH1-overexpressing cells. To clarify SASH1 function, a fusion GFP vector encoding SASH1 was introduced into A-375 cells. GFP was detected by fluorescence microscopy (Fig. 1A). GFP was diffusely located in the nucleus and cytoplasm in the A-375 (EGFP) and A-375 (SASH1) cells. The stable cell line [A-375 (SASH1)] was further confirmed by western blot analysis. As shown in Fig. 1B, the film blotted by SASH1 antibody reveals the SASH1 fusion protein, 2 bands displayed near the size of $170 \mathrm{kDa}$ in the A-375 (SASH1) cells, of which, one was the fusion protein, while the other original protein. Furthermore, the film blotted by GFP antibody, at the size of $170 \mathrm{kDa}$ displayed a band. All these data proved that the stable cell lines A-375 (SASH1) and A-375 (EGFP) were successfully established.

Effects of SASH1 gene on G2/M phase cell cycle arrest in A-375 cells. Cell proliferation assay showed that A-375 (SASH1) cell viability was the lowest among the 3 groups of cells. A-375 (EGFP) cell viability was not significantly diminished compared with the A-375 cells. Statistical analysis indicated that there was a significant difference $(\mathrm{p}<0.001)$ between the A-375 (SASH1), A-375 (EGFP) and A-375 cells (Fig. 2). These results suggest that the gene SASH1 inhibits cell proliferation.

To assess whether cell apoptosis is also involved in the inhibition of cell proliferation, DAPI staining experiment was conducted. As shown in Fig. 3, a slight nuclear fragmentation or chromatin condensation was observed in the A-375 (SASH1), A-375 (EGFP) and A-375 cells. At the same time, Annexin V-FITC and PI staining assay also demonstrated that there was no statistically significant difference in the apop- 
Table I. Primers used for real-time PCR.

\begin{tabular}{|c|c|c|c|}
\hline Genes & Primers & Sequences $\left(5^{\prime}-3^{\prime}\right)$ & Length (bp) \\
\hline TP53 & $\begin{array}{l}\text { p53 sense } \\
\text { p53 antisense }\end{array}$ & $\begin{array}{l}\text { TCTTTGAACCCTTGCTTGC } \\
\text { TCСТАСТССССАТССТССТC }\end{array}$ & 132 \\
\hline$C D K 1$ & $\begin{array}{l}\text { Cdc2 sense } \\
\text { Cdc2 antisense }\end{array}$ & $\begin{array}{l}\text { TGTCCGCAACAGGGAAGAAC } \\
\text { CGAAAGCCAAGATAAGCAACTC }\end{array}$ & 140 \\
\hline$C C N B 1$ & $\begin{array}{l}\text { CCNB1 sense } \\
\text { CCNB1 antisense }\end{array}$ & $\begin{array}{l}\text { GTAAGCCAAGTCATGGAGAATC } \\
\text { GCAGCAATCACAAGAAGAAAC }\end{array}$ & 105 \\
\hline WEE1 & $\begin{array}{l}\text { WEE1 sense } \\
\text { WEE1 antisense }\end{array}$ & $\begin{array}{l}\text { TGTTACACCAGCCTTTCCAG } \\
\text { ATGAGTCTTTTAGCATGTCCCT }\end{array}$ & 168 \\
\hline GAPDH & $\begin{array}{l}\text { GAPDH sense } \\
\text { GAPDH antisense }\end{array}$ & $\begin{array}{l}\text { CAAGAAGGTGGTGAAGCAGG } \\
\text { CGTCAAAGGTGGAGGAGTGG }\end{array}$ & 116 \\
\hline
\end{tabular}
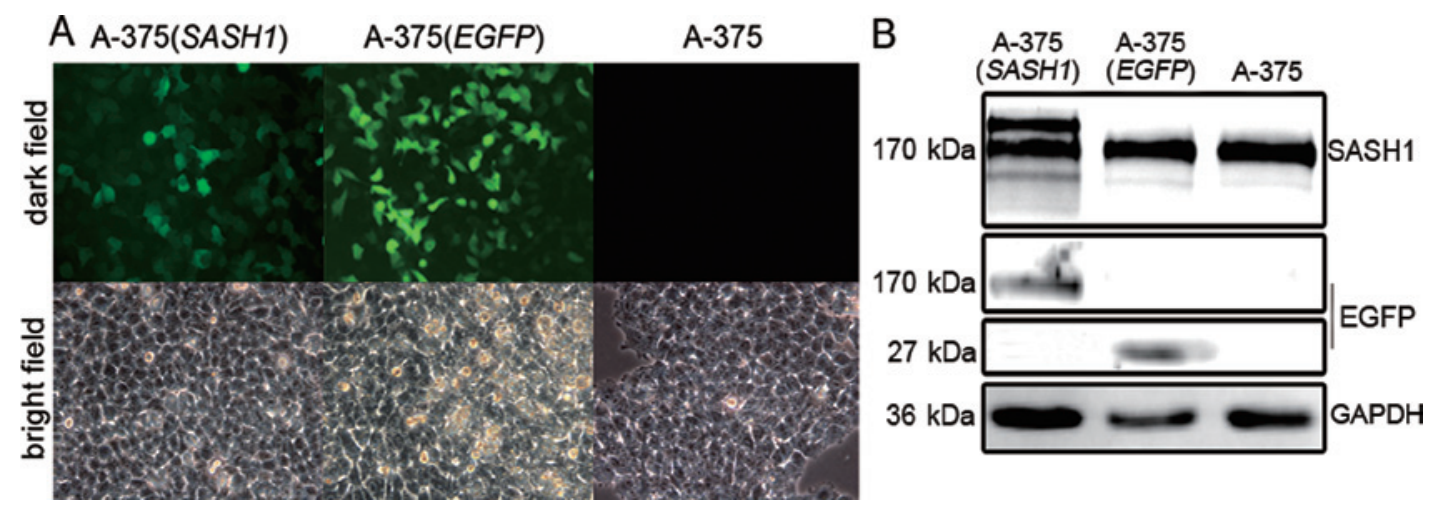

Figure 1. Generation of the stable cell line with SASH1 overexpression. (A) The expression of SASH1 fusion protein and GFP observed under a fluorescence phasecontrast microscope in the 3 groups of cells (x10). (B) SASH1 fusion protein detected by western blot analysis, incubated with SASH1 antibody or GFP antibody.

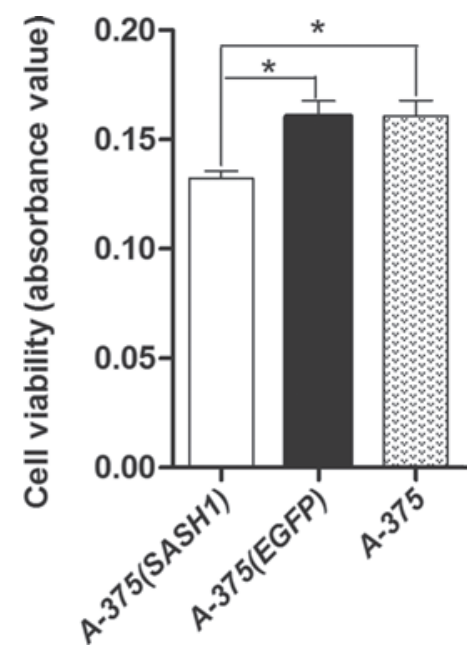

Figure 2. SASH1 gene significantly suppressed cell viability. Values are expressed as the means $\pm \mathrm{SD}$. from 3 independent experiments $($ " $\mathrm{p}<0.001)$.

totic rate between any 2 groups of the A-375 (SASH1), A-375 (EGFP) and A-375 cells. Based on these data, it is evident that cell apoptosis did not participate in the inhibition of cell proliferation.

In order to reveal the underlying mechanism behind the inhibition of cell proliferation, cell cycle assay was performed.
Flow cytometric analysis showed that the number of A-375 (SASH1) cells was significantly increased in the G2/M and $\mathrm{S}$ fractions accompanied by an evident decrease in the number of cells in G0/G1 compared to the A-375 (EGFP) and A-375 cells. However, when comparing the A-375 (EGFP) with the A-375 cells, no statistically significant difference was observed in cell numbers at the G0/G1, S or G2/M phase (Fig. 4).

In order to determine the mechanism behind the $\mathrm{G} 2 / \mathrm{M}$ phase cell cycle arrest, the mRNA expression of the CCNB1, CDK1, TP53 and WEE1 genes was quantified in the A-375 (SASH1), A-375 (EGFP) and A-375 cells by real-time RT-PCR. In the A-375 (SASH1) cells, the expression of CCNB1 and CDK1 was significantly increased $(\mathrm{p}<0.001)$ as opposed to the A-375 (EGFP) and A-375 cells, whereas the expression of CCNB1 and CDK1 in the A-375 (EGFP) cells was evidently $(\mathrm{p}<0.001)$ decreased compared to the A-375 cells (Fig. 5). In particular, compared to the A-375 (SASH1) cells, the expression of CCNB1 and CDK1 in the A-375 (EGFP) cells was decreased by 4- and 2.5-fold, respectively. As for the TP53 gene, its expression in the A-375 (SASH1) and A-375 (EGFP) cells was dramatically lower compared to the A-375 cells $(\mathrm{p}<0.001)$, although no statistically significant difference was observed between the A-375 (SASH1) and A-375 (EGFP) cells. As for the WEE1 gene (Fig. 5), no statistically significant difference was observed when comparing any any 2 of the 3 groups. 

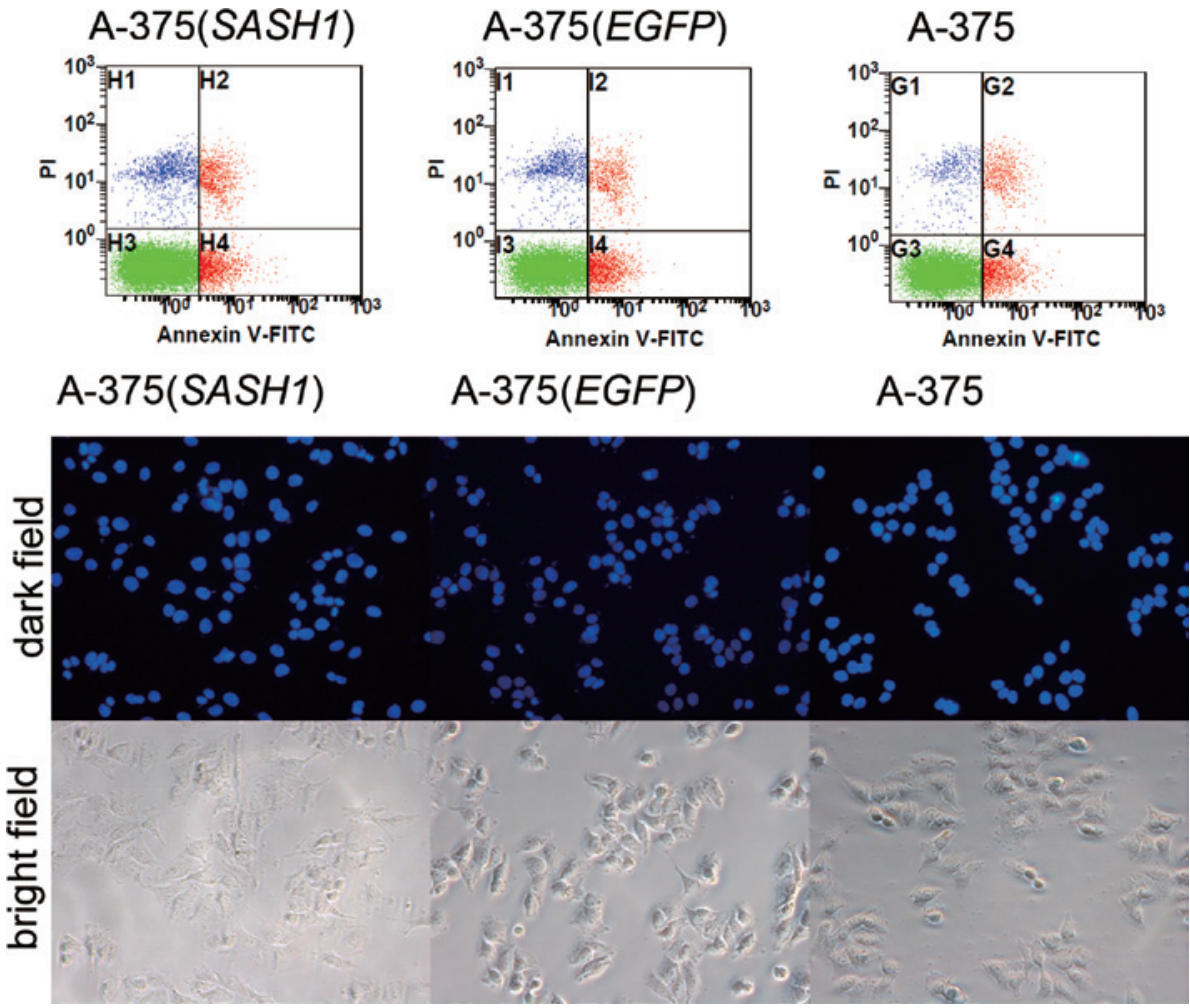

Figure 3. Apoptosis analysis by Annexin V-FITC and PI staining assay (top panel) or DAPI staining in the 3 groups of cells (bottom panel).

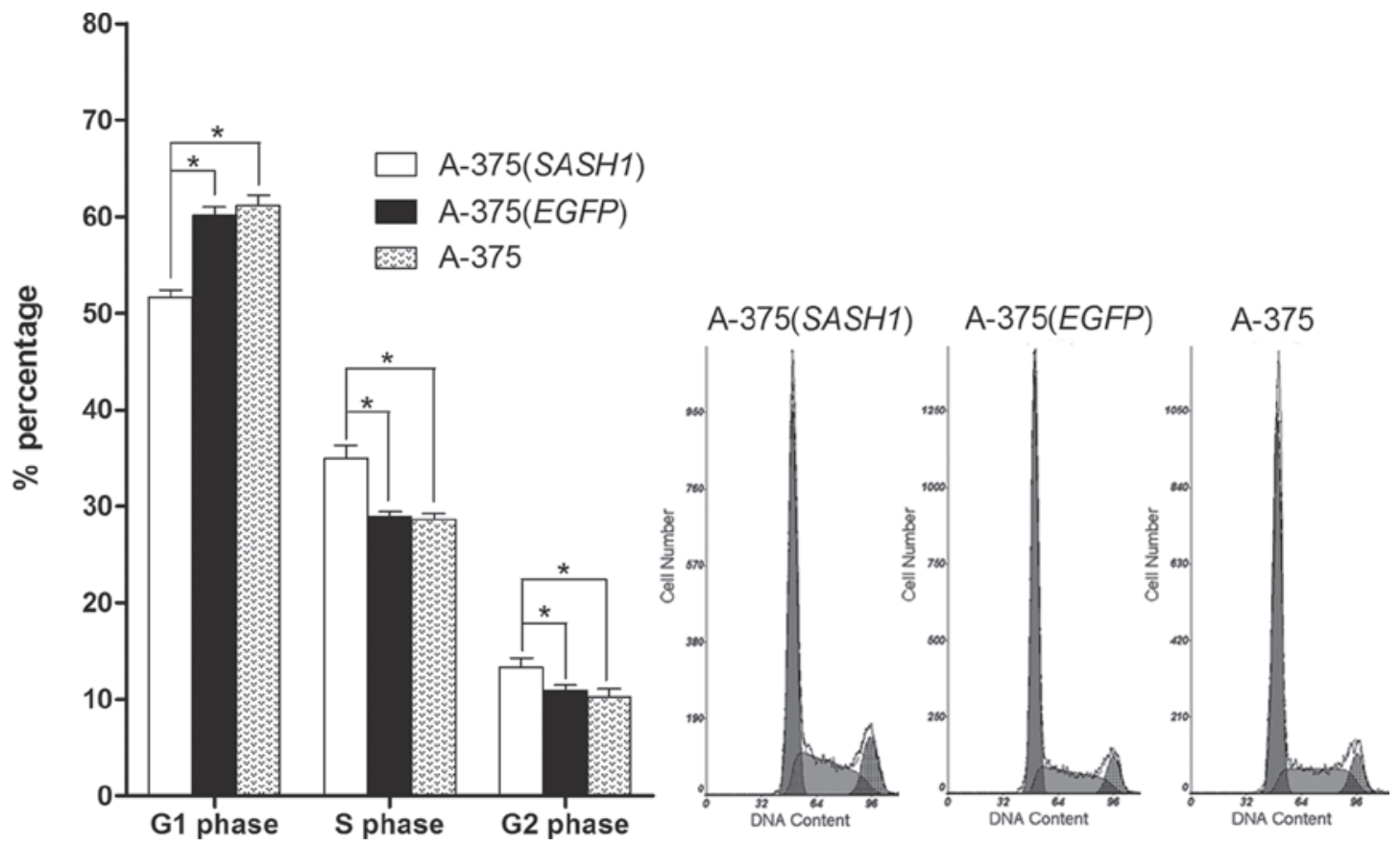

Figure 4. Overexpression of SASH1 induced G2/M arrest in A-375 cells. Values were expressed as the means \pm SD. from 4 independent experiments ("p $<0.001$ ). Histograms of the cell cycle are shown (left panel) in the 3 groups of cells.

\section{Discussion}

The expression of SASH1, a potential tumor suppressor gene, is either decreased or lost in many types of cancer $(12,13)$. Based on the characteristics of the domains within the SASH1 protein, SASH1 may play an important role in intracellular signaling and transcriptional regulation. Rimkus et al demon- strated that SASH1 plays a crucial role in tumorigenesis, development, invasion and metastasis. The decrease in SASH1 expression correlates with the formation of metachronous distant metastases (13). In another study, Martini et al also demonstrated that SASH1 interacts with the actin cytoskeleton and stimulates cell-matrix adhesion (10). Clinical research has also documented that the SASH1 mRNA expression level is 


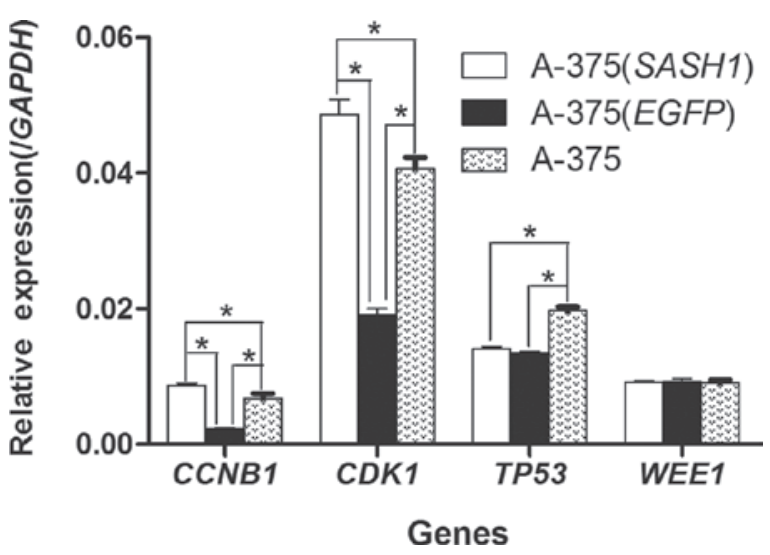

Figure 5. mRNA expression levels of CCNB1, CDK1, TP53 and WEE1 were examined using quantitative real-time PCR. The results were expressed as the ratio of copies of the target gene relevant to GAPDH from 4 independent experiments. Data were expressed as the means \pm SD. ${ }^{*} \mathrm{p}<0.001$.

significantly reduced in $70 \%$ of breast cancer samples (12). Moreover, the SASH1 mRNA expression level is also significantly reduced in primary lung cancer and thyroid cancer, while the size of the decrease correlates with the prognosis and tumor size (13). Chen et al proved that SASH1 inhibits cell proliferation and enhances cell apoptosis in the A549 lung cancer cell line (11). All these data suggest that SASH1 plays a crucial role in tumorigenesis, growth and evolution. However, there are few studies available on the role of SASH1 in the tumorigenesis and development of melanoma. Therefore, we used in vitro studies to investigate the role of the SASH1 gene in A-375 melanoma cells.

An A-375 stable melanoma cell line was established, overexpressing the SASH1 gene and cell proliferation assay indicated that the viability of the A-375 (SASH1) cells was significantly decreased $(\mathrm{p}<0.05)$ compared to that of the A-375 (EGFP) and A-375 cells. These results suggest that SASH1 inhibits cell proliferation. In order to clarify the underlying mechanism behind the inhibition of cell proliferation, Annexin V-FITC and PI staining, as well as DAPI staining were performed to assess cell apoptosis. The results demonstrated that cell apoptosis did not account for the inhibition of cell proliferation. Subsequent to the cell cycle analysis conducted, the results proved that the SASH1 gene decreased the percentage of cells in the G1 phase and arrested cells at the G2/M checkpoint, inducing a significant accumulation of cells in the $\mathrm{S}$ phase. These results suggest that the inhibition of proliferation by SASH1 occurs by $\mathrm{G} 2 / \mathrm{M}$ arrest in the A-375 cells.

The pivotal regulatory step for $\mathrm{G} 2 / \mathrm{M}$ transition in eucaryotes is the activation of the cell division cycle $\mathrm{Cdc} 2 /$ cyclin B complex $(14,15)$. Cdc2/cyclin B is maintained in an inactive form during the $\mathrm{S}$ and $\mathrm{G} 2$ phases by the inhibitory phosphorylation of the Cdc2 residues, threonine 14 (Thr14) and tyrosine 15 (Tyr15) (16). The inhibitory phosphorylation of Cdc2 is modulated by the WEE1 family protein kinases (human WEE1 and Myt1). The dephosphorylation of the Thr14 and Tyr15 residues of $\mathrm{Cdc} 2$ by $\mathrm{Cdc} 25 \mathrm{~B}$ (in the cytoplasm) and $\mathrm{Cdc} 25 \mathrm{C}$ (in the nucleus) in the late $\mathrm{G} 2$ phase activates the cyclin $\mathrm{B} / \mathrm{Cdc} 2$ complex, and the accumulated, active $\mathrm{Cdc} 2 /$ cyclin B1 then triggers the initiation of mitosis (17). The cyclin B-Cdc2 kinase is the master regulator of cell cycle progression. The anomalous regulation of this complex or enhanced expression of cyclin $\mathrm{B}$ has been demonstrated to be associated with several cellular malfunctions, including G2/M arrest and apoptosis $(18,19)$.

On the basis of $\mathrm{G} 2 / \mathrm{M}$ transition, the possible genes related to $\mathrm{G} 2 / \mathrm{M}$ transition were analyzed by real time PCR. Our results demonstrated that the mRNA expression of cyclin B (CCNB1) and $\mathrm{Cdc} 2$ (CDK1) increased by 4 - and 2.5-fold, respectively in the A-375 (SASH1) cells compared with the A-375 (EGFP) cells. The $\mathrm{G} 2 / \mathrm{M}$ arrest mostly resulted from the inhibition of the expression of cyclin B or Cdc2 $(20,21)$. However, our findings suggested that SASH1 enhanced $\mathrm{G} 2 / \mathrm{M}$ arrest via the upregulation of cyclin B and Cdc2. The cyclin B-Cdc2 kinase is usually kept in an inactive state by the inhibitory phosphorylation of the Cdc2 residues, Thr14 and Tyr15, until the $\mathrm{G} 2 / \mathrm{M}$ transition $(17,22)$. Thus, we hypothesized that the phosphorylation of $\mathrm{Cdc} 2$ may be responsible for the G2/M arrest. The inhibitory phosphorylation of Cdc2 is modulated by the WEE1 family protein kinases (human WEE1 and Myt1). The WEE1 gene product is a tyrosine-specific protein kinase, located in the nucleus and phosphorylates Cdc2 exclusively at Tyr15 (23). Nevertheless, there was no difference in the expression of the WEE1 gene in any 2 of the 3 cell lines in the present study. Therefore, we hypothesized that the crucial role in the phosphorylation of Cdc2 may be played by Myt1. Myt1, as a homologue of the product of the mik1 gene, is a dual-specificity protein kinase that phosphorylates $\mathrm{Cdc} 2$ at both Thr14 and Tyr15 residues (16). Apart from the inhibitory phosphorylation of $\mathrm{Cdc} 2$, Myt1 seems to influence the normal shuttling of the Cdc2/cyclin B complex into the nucleus (17). On these grounds, we hypothesized that the phosphorylation of Cdc2 by Myt1 suppressed its catalytic activity or stopped the shuttling of the $\mathrm{Cdc} 2 /$ cyclin B complex into the nucleus, which led to G2/M arrest in the A-375 (SASH1) cells. At the same time, the overexpression of cyclin B also contributed to Cdc2 phosphorylation (18). Nevertheless, additional investigations are required in order to delineate the influences of SASH1 on Myt1, including promoting its expression or inhibiting its degradation. Cdc25 family members, which are dual-specificity phosphatases, have been identified as positive regulators of $\mathrm{Cdc} 2$. To make $\mathrm{Cdc} 2$ kinase active and facilitate the entry of cells from G2 to mitosis, Thr14 and Tyr15 (the 2 residues of $\mathrm{Cdc} 2$ ) are dephosphorylated by active $\mathrm{Cdc} 25 \mathrm{C}$ phosphatase (18). Consequently, the inactivation or alterations in Cdc25C phosphatase activity may be another reason for cell cycle arrest in the G2/M phase in the A-375 (SASH1) cells. Activated Chk1 has been reported to lead to the inhibitory phosphorylation of Cdc25C on Ser-216, and subsequently to the inactivation of $\mathrm{Cdc} 25$ (24).

Apart from the phosphorylation of $\mathrm{Cdc} 2$, the inhibition of cyclin B-Cdc2 binding may also stop cell entry from $\mathrm{G} 2$ to mitosis (25). In the present study, cyclin B and Cdc2 were both overexpressed in the A-375 (SASH1) cells. In view of the above, we assumed that the SASH1 gene possibly blocked cyclin B1-Cdc2 binding, either directly or indirectly, leading to G2/M arrest. Although p53 can affect cyclin B1/Cdc2 activity, resulting in G2/M arrest (26-28), no statistically significant difference was observed in the TP53 mRNA level between the A-375 (SASH1) and A-375 (EGFP) cells. Therefore, it did not account for the G2/M arrest. In the present study, we demon- 
strate the tumor suppressive effects of SASH1 by G2/M arrest in A-375 cells. However, additional investigations are required in order to clarify the exact mechanism involved.

In conclusion, the present study indicates that the tumor inhibitory effects of SASH1 occur by G2/M arrest in A-375 cells (Fig. 4). Although the exact mechanism involved remains unclear, our results show that p53 and WEE1 are not involved in the $\mathrm{G} 2 / \mathrm{M}$ arrest and demonstrate that $\mathrm{G} 2 / \mathrm{M}$ arrest correlates with $\mathrm{Cdc} 2$ phosphorylation or the inhibition of cyclin B-Cdc2 binding.

\section{Acknowledgements}

The authors are grateful to all the participants in this study. This study was supported by a grant from the National Natural Science Foundation of China (No: 90919049), the 973 Program (2010CB529600, 2007CB947300), the Shanghai Municipal Commission of Science and Technology Program (09DJ1400601) and the third phase of the 211 project of the Ministry of Education of China. Sponsors we not involved with the study design, data collection and analysis, decision to publish or the preparation of the manuscript.

\section{References}

1. Villanueva A and Llovet JM: Targeted therapies for hepatocellular carcinoma. Gastroenterology 140: 1410-1426, 2011.

2. Jousilahti P, Salomaa V, Kuulasmaa K, Niemela M and Vartiainen E: Total and cause specific mortality among participants and non-participants of population based health surveys: a comprehensive follow up of 54372 Finnish men and women. J Epidemiol Community Health 59: 310-315, 2005.

3. Gray L, Batty GD, Craig P, et al: Cohort profile: the Scottish health surveys cohort: linkage of study participants to routinely collected records for mortality, hospital discharge, cancer and offspring birth characteristics in three nationwide studies. Int J Epidemiol 39: 345-350, 2010

4. Veeck J, Niederacher D, An H, et al: Aberrant methylation of the Wnt antagonist SFRP1 in breast cancer is associated with unfavourable prognosis. Oncogene 25: 3479-3488, 2006.

5. Beaumont $\mathrm{T}$ and Leadbeater M: Treatment and care of patients with metastatic breast cancer. Nurs Stand 25: 49-56, 2011.

6. Dai $\mathrm{C}$ and $\mathrm{Gu} \mathrm{W}: \mathrm{p} 53$ post-translational modification: deregulated in tumorigenesis. Trends Mol Med 16: 528-536, 2010.

7. Zegarra-Moro OL, Schmidt LJ, Huang $\mathrm{H}$ and Tindall DJ: Disruption of androgen receptor function inhibits proliferation of androgen-refractory prostate cancer cells. Cancer Res 62 1008-1013, 2002.

8. Zhang H, Pan Y, Zheng L, et al: FOXO1 inhibits Runx2 transcriptional activity and prostate cancer cell migration and invasion. Cancer Res 71: 3257-3267, 2011.

9. Zhao Y, Kong X, Li X, et al: Metadherin mediates lipopolysaccharide-induced migration and invasion of breast cancer cells PLoS One 6: e29363, 2011.
10. Martini M, Gnann A, Scheikl D, Holzmann B and Janssen KP: The candidate tumor suppressor SASH1 interacts with the actin cytoskeleton and stimulates cell-matrix adhesion. Int J Biochem Cell Biol 43: 1630-1640, 2011.

11. Chen EG, Chen Y, Dong LL and Zhang JS: Effects of SASH1 on lung cancer cell proliferation, apoptosis, and invasion in vitro. Tumour Biol: April 10, 2012 (E-pub ahead of print)

12. Zeller C, Hinzmann B, Seitz S, et al: SASH1: a candidate tumor suppressor gene on chromosome 6q24.3 is downregulated in breast cancer. Oncogene 22: 2972-2983, 2003.

13. Rimkus C, Martini M, Friederichs J, et al: Prognostic significance of downregulated expression of the candidate tumour suppressor gene SASH1 in colon cancer. Br J Cancer 95: 1419-1423, 2006.

14. Coleman TR and Dunphy WG: Cdc2 regulatory factors. Curr Opin Cell Biol 6: 877-882, 1994.

15. Morgan DO: Cyclin-dependent kinases: engines, clocks, and microprocessors. Annu Rev Cell Dev Biol 13: 261-291, 1997.

16. Krek W and Nigg EA: Mutations of p34cdc2 phosphorylation sites induce premature mitotic events in HeLa cells: evidence for a double block to $\mathrm{p} 34 \mathrm{cdc} 2$ kinase activation in vertebrates. EMBO J 10: 3331-3341, 1991

17. Dai X, Yamasaki K, Yang L, et al: Keratinocyte G2/M growth arrest by 1,25-dihydroxyvitamin D3 is caused by Cdc2 phosphorylation through Wee1 and Myt1 regulation. J Invest Dermatol 122: 1356-1364, 2004

18. Ray G, Dhar G, Van Veldhuizen PJ, et al: Modulation of cell-cycle regulatory signaling network by 2 -methoxyestradiol in prostate cancer cells is mediated through multiple signal transduction pathways. Biochemistry 45: 3703-3713, 2006.

19. Liu X, He H, Feng Y, Zhang M, Ren K and Shao R: Difference of cell cycle arrests induced by lidamycin in human breast cancer cells. Anticancer Drugs 17: 173-179, 2006.

20. Seo HR, Lee DH, Lee HJ, et al: Cyclin G1 overcomes radiationinduced $\mathrm{G} 2$ arrest and increases cell death through transcriptional activation of cyclin B1. Cell Death Differ 13: 1475-1484, 2006.

21. Tang L, Zhang Y, Pan H, et al: Involvement of cyclin B1 in progesterone-mediated cell growth inhibition, G2/M cell cycle arrest, and apoptosis in human endometrial cell. Reprod Biol Endocrinol 7: 144, 2009.

22. Passalaris TM, Benanti JA, Gewin L, Kiyono T and Galloway DA: The $\mathrm{G}(2)$ checkpoint is maintained by redundant pathways. Mol Cell Biol 19: 5872-5881, 1999.

23. McGowan $\mathrm{CH}$ and Russell P: Cell cycle regulation of human WEE1. EMBO J 14: 2166-2175, 1995.

24. Wang XM, Li J, Feng XC, Wang Q, Guan DY and Shen ZH: Involvement of the role of Chk1 in lithium-induced G2/M phase cell cycle arrest in hepatocellular carcinoma cells. J Cell Biochem 104: 1181-1191, 2008.

25. Ryu MS, Lee MS, Hong JW, Hahn TR, Moon E and Lim IK: TIS21/BTG2/PC3 is expressed through PKC-delta pathway and inhibits binding of cyclin B1-Cdc2 and its activity, independent of p53 expression. Exp Cell Res 299: 159-170, 2004.

26. Paulsen MT, Starks AM, Derheimer FA, et al: The p53-targeting human phosphatase hCdc14A interacts with the Cdk1/cyclin B complex and is differentially expressed in human cancers. Mol Cancer 5: 25, 2006.

27. Bunz F, Dutriaux A, Lengauer C, et al: Requirement for $\mathrm{p} 53$ and p21 to sustain G2 arrest after DNA damage. Science 282: 1497-1501, 1998

28. Yang PM, Huang WC, Lin YC, et al: Loss of IKKbeta activity increases p53 stability and p21 expression leading to cell cycle arrest and apoptosis. J Cell Mol Med 14: 687-698, 2010. 